\title{
Feasibility of Upfront Debulking Surgery versus Neoadjuvant Chemotherapy Followed by Interval Debulking Surgery for Advanced Ovarian Cancer
}

\author{
Amen Hamdy Zaky1, Adel Gabr ${ }^{1}$, Doaa Wadie Maximous², Ahmed A. S. Salem², \\ Amr Farouk Mourad ${ }^{3}$, Haisam Atta ${ }^{3}$, Marwa Ismail ${ }^{4}$ \\ ${ }^{1}$ Medical Oncology Department, South Egypt Cancer Institute, Assiut University, Assiut, Egypt \\ ${ }^{2}$ Surgical Oncology Department, South Egypt Cancer Institute, Assiut University, Assiut, Egypt \\ ${ }^{3}$ Radiadiagnosis Department, South Egypt Cancer Institute, Assiut University, Assiut, Egypt \\ ${ }^{4}$ Clinical Oncology Department, Faculty of Medicine, Assiut University, Assiut, Egypt \\ Email: *adelgabre@yahoo.com
}

How to cite this paper: Zaky, A.H., Gabr, A., Maximous, D.W., Salem, A.A.S., Mourad, A.F., Atta, H. and Ismail, M. (2018) Feasibility of Upfront Debulking Surgery versus Neoadjuvant Chemotherapy Followed by Interval Debulking Surgery for Advanced Ovarian Cancer. Journal of Cancer Therapy, 9, 145-155.

https://doi.org/10.4236/jct.2018.92015

Received: January 26, 2018

Accepted: February 23, 2018

Published: February 26, 2018

Copyright $\odot 2018$ by authors and Scientific Research Publishing Inc. This work is licensed under the Creative Commons Attribution International License (CC BY 4.0).

http://creativecommons.org/licenses/by/4.0/

\begin{abstract}
Background: Inappropriately ovarian cancer cannot be detected until an advanced stage. Radical debulking surgery is considered the cornerstone in the management of advanced ovarian cancer pointing to complete tumor resolution. Unless optimal debulking cannot be achieved, these patients gain little benefit from surgery. Neoadjuvant chemotherapy (NACT) has been recommended as a novel therapeutic modality to a diversity of malignant tumors when the disease is not willing to optimal surgical resection at the time of diagnosis or the patient who unfit for aggressive debulking surgery. The purpose of this study is to compare survival in the patient with advanced ovarian cancer (stage III/IV) underwent primary debulking surgery followed by adjuvant chemotherapy (PDS-ACTR) to those who received neoadjuvant chemotherapy followed by interval debulking surgery (NACT-IDS). Results: Neoadjuvant chemotherapy (NACT-IDS) showed significant complete cytoreduction and decreased in surgical morbidity in comparison to primary debulking surgery (PDS-ACTR). NACT-IDS showed significant improvement in progression-free survival (P-value 0.002) and overall survival (P-value 0.03 ) in comparison to PDS-ACTR. Response to NACT and residual volume were the two independent prognostic factors for overall survival. Conclusion: NACT-IDS for advanced ovarian cancer (III/IV) resulted in higher frequency of complete resection with no residual tumor, less post-operative surgical morbidity and
\end{abstract}


significant increase progression-free survival and overall survival. Both responses to NACT and residual tumor volume were the two independent prognostic factors for survival in ovarian cancer.

\section{Keywords}

Advanced Ovarian Cancer, Debulking Surgery, Neoadjuvant Chemotherapy

\section{Introduction}

The fifth most common cancer among women is ovarian cancer, and approximately, half of the ovarian cancer patients die from the disease instituting it as the fourth most common cause of gynecologic cancer-related death in most industrialized countries [1] [2]. Early staging ovarian cancer confined to the ovary may have few or no symptoms, making its clinical diagnosis and management more difficult and symptoms were most commonly seen with the advanced disease. $\leq 30 \%$ of the patients with apparently early epithelial ovarian cancer might be upstaged after comprehensive surgical staging [3] [4]. Previous reports by Cass et al. and Maggioni et al. showed that patients with even early ovarian tumor confined to ovary might have pelvic or even Para aortic lymph nodes metastases which making systemic lymphadenectomy improving progression-free survival and disease-free survival [5] [6]. Although advances in diagnosis and management of epithelial ovarian cancer have changed in the last 25 years, the overall survival has not been improved as approximately $65 \%$ to $70 \%$ of all ovarian cancer continues to be diagnosed with advanced stage (III or IV). Primary optimal debulking surgery has become the standard step in the management of advanced epithelial ovarian cancer [7]. When optimal debulking cannot be achieved, little benefit from debulking surgery will be gained [8]. Neoadjuvant chemotherapy (NACT) has been anticipated as a novel therapeutic modality to a diversity of solid tumors when the disease is not amenable to radical surgical resection at the time of diagnosis or those who are unhealthy for aggressive debulking surgery [9]. NACT has been accepted as a useful approach for the treatment of various advanced cancers [10] [11]. In cases with advanced ovarian cancer, platinum-based chemotherapy regimens have been established to produce highest response rates and a statistically significant survival advantages compared with drug regimens without platinum [12] [13]. Recently, the results of a large phase III trial reported that women with stages IIIC and IV EOC randomized to NACT followed by debulking surgery (NACT-IDS) had the same survival as women undergoing PDS followed by chemotherapy (PDS-CTR) [14].

The purpose is to compare survival in the patient with advanced ovarian cancer (III/IV) underwent primary debulking surgery (PDS-CTR) followed by chemotherapy to those who received neoadjuvant chemotherapy followed by interval debulking surgery (NACT-IDS). 


\section{Patients and Method}

A noncontrolled interventional randomized prospective study, including patients diagnosed with advanced ovarian cancer (III/IV) in South Egypt Cancer Institute and Oncology department in As suit University hospital from April 2012 to March 2016. Each of the consecutive patients chose a closed envelope containing the number of the assigned group. Ethical approval waived and informed written consent obtained from each patient.

The diagnosis based on radiological studies, Cytology from as cites, histopathology obtained by tumor biopsy and tumor marker (CA125) is set to be more than $200 \mathrm{U} / \mathrm{ml}$. We excluded patients with previous history of chemotherapy or radiotherapy for other malignancy, the patients with a history of organ dysfunction and poor performance status.

Patients in the study divided into two groups:

- Neoadjuvant Chemotherapy Arm (NACT-IDS, the group I)

Four cycles of chemotherapy regimen (TC) paclitaxel $\left(175 \mathrm{mg} / \mathrm{m}^{2}\right.$, Day 1$)$ and carboplatin (AUC 5, Day 1) were administered every three weeks followed by Interval debulking surgery (complete surgical resection include panhysterectomy, pelvic and para-aortic lymph node dissection, omentectomy, appendectomy and small or large bowel resection unless disease progression occurs followed by another four cycles.

\section{- Standard Treatment Arm (PDS-ACTR, group II)}

Primary debulking surgery is performed firstly including panhysterectomy followed by postsurgical chemotherapy (PDS-ACTR) of six to eight cycles of taxanes based regimen (TC), is administered every three weeks

\section{- Imaging studies}

All patients included in the study performed imaging for diagnosis and staging at the time of admission. Modalities employed included. Abdominal and transvaginal sonography with color flow mapping (Figure 1), post contrast Multidetector CT (MDCT) (Figure 2) and MRI with diffusion are reserved for indeterminate cases.

For the sake of follow up; patients in group I Post contrast MDCT is performed after the first four cycles of administration of the chemotherapeutic agents and after finishing the regimen before surgical intervention (Figure 3 ). Afterwards routine follow up was carried out after four weeks from the time of operation to assess the presence of residual disease.

While for Group II; Imaging performed after the operative intervention to assess residual disease if present and to create a new baseline before applying the chemotherapy (Figure 4).

For both groups, Follow up was carried out with a routine clinical and radiological assessment where imaging is performed routinely after finishing three consecutive doses of chemotherapy (average every ten weeks). Response evaluation criteria employed with RECIST (response evaluation criteria in solid tumors) version 1.1 . 


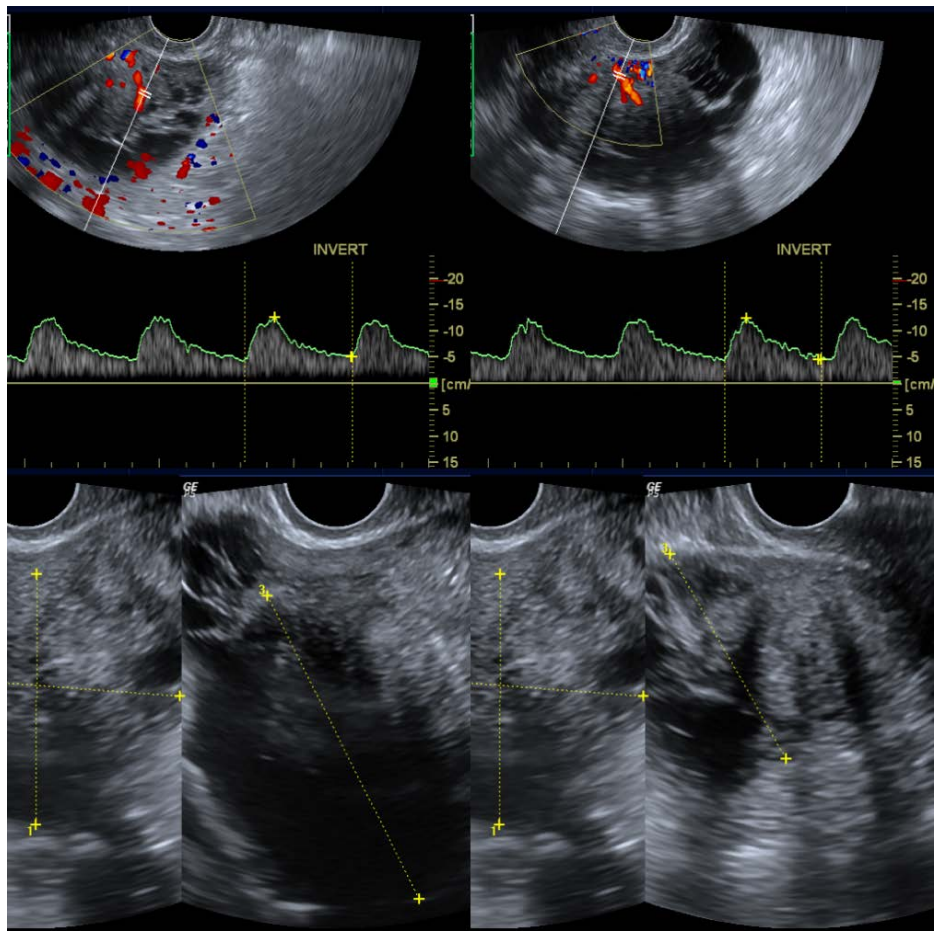

Figure 1. Transvaginal sonoraphy of a malignant featuring right mixed ovarian mass lesion with increased vascularity in color flow mapping.

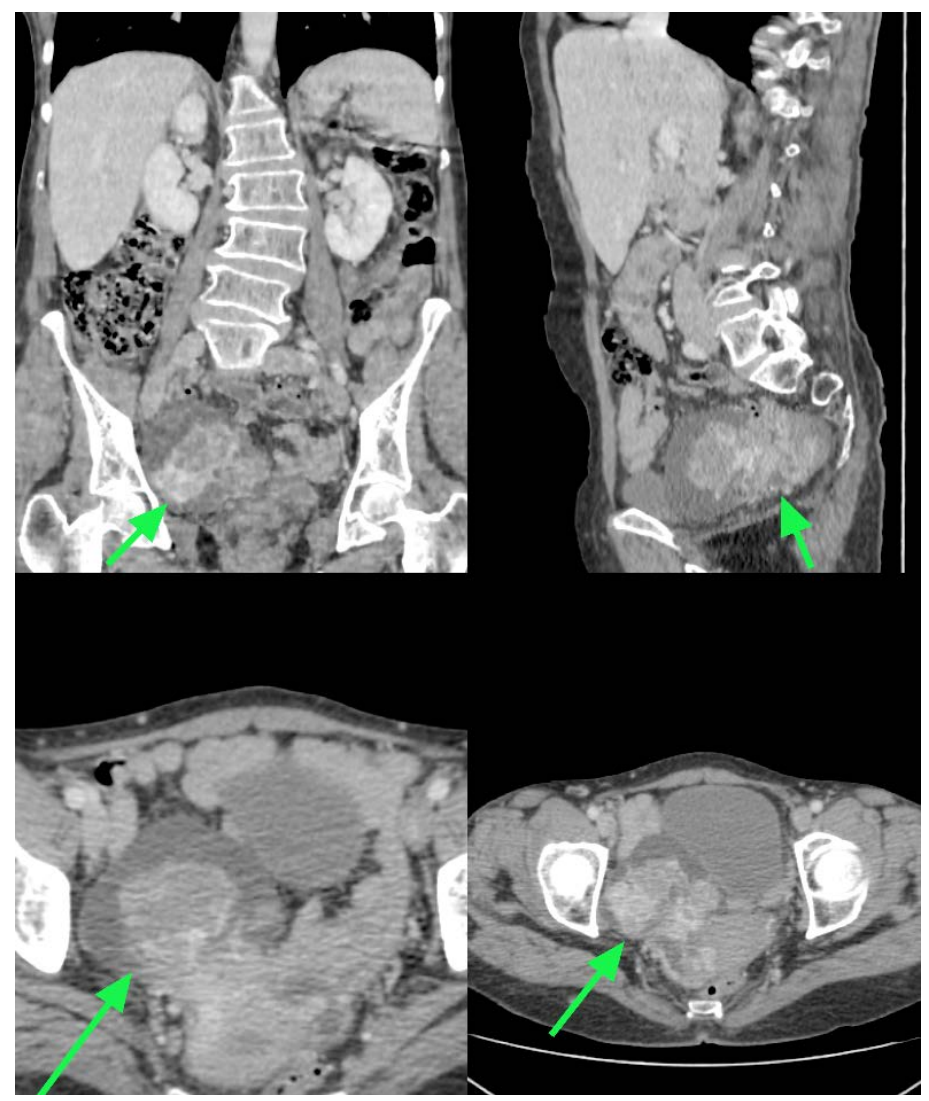

Figure 2. Post contrast MDCT of a malignant featuring right ovarian mass lesion of mixed nature (green arrow) and evident pelvic peritoneal deposites $>2 \mathrm{~cm}$ in size. 


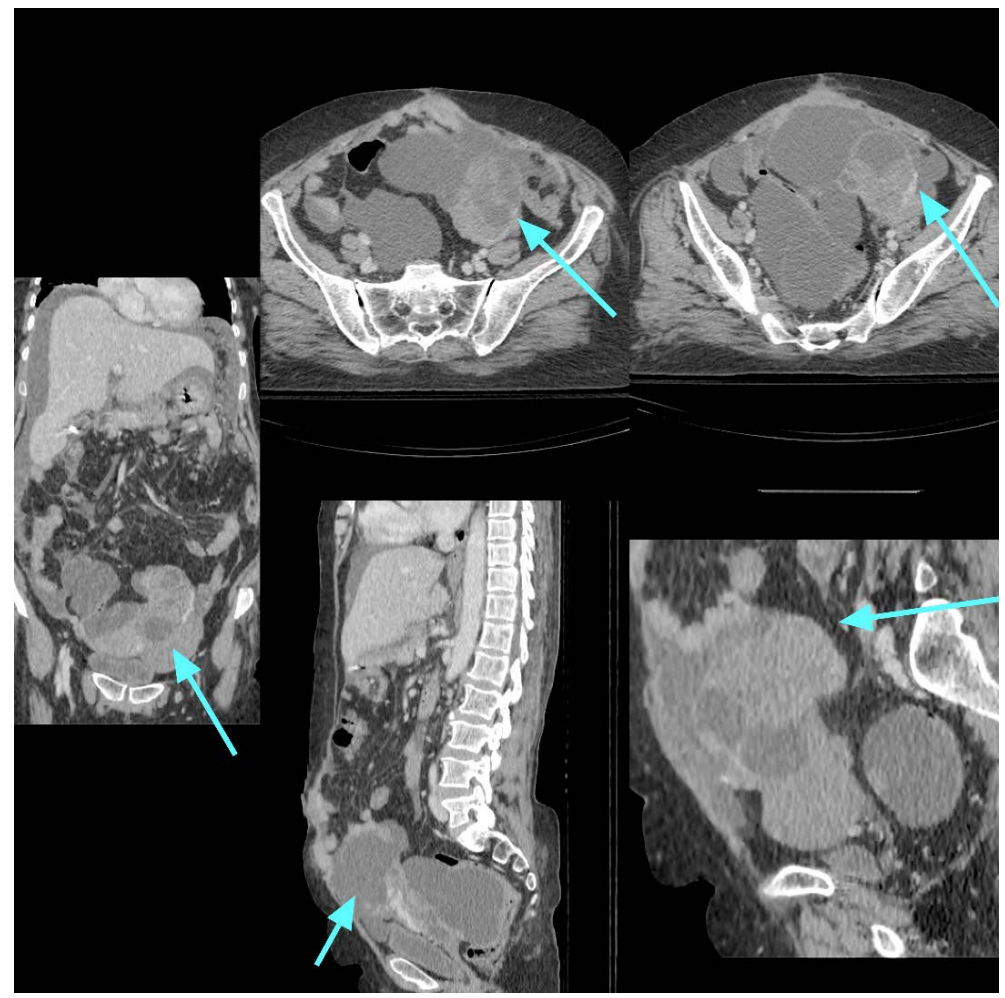

Figure 3. Post contrast MDCT of a malignant featuring left ovarian mass lesion of mixed nature and heterogenous enhancement (blue arrow) and evident peritoneal deposites posterior to anterior abdominal wall.
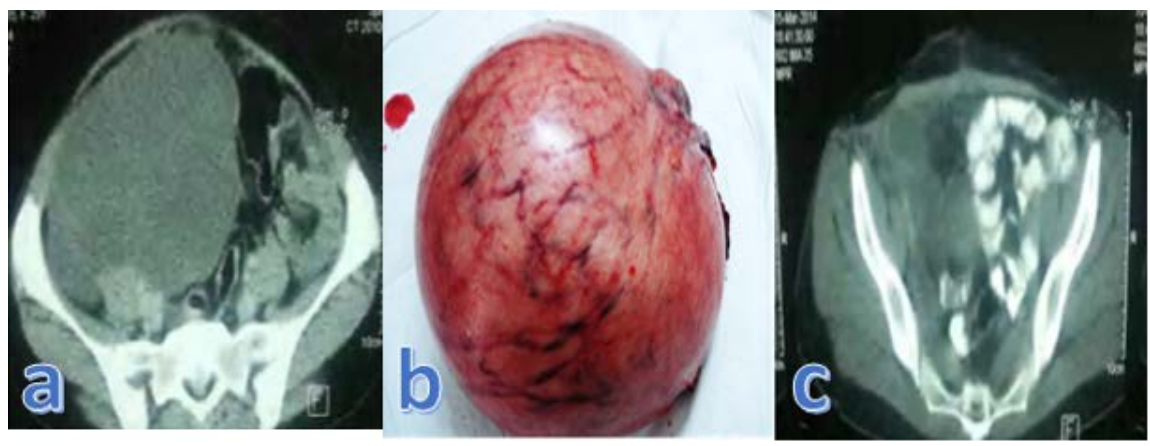

Figure 4. (a) Before chemotherapy: Right large pelviabdominal mass about $6 \times 8 \mathrm{~cm}$, mixed solid and cystic components. The lesion extends laterally with no line of separation with right iliopsoas muscle suggestive of infiltration and extends anteriorly with a clear fatty line of separation with the anterior abdominal wall, and the lesion compresses the adjacent bowel loops with multiple pelvic peritoneal deposits; (b) Apostoperative specimen of panhysterectomy of large Rt. ovarian mass; (c) After chemotherapy: Marked significant reduction of the size and extension. No definite infiltrationof the right iliopsoas muscle with complete pacifications of the related bowel loops with any mass effect on it.

\section{- Statistical Analysis}

Comparisons among groups performed with the t-test and the Fisher's exact test. The test was two sides. The result considered significant at $\mathrm{P}<0.05$. The Kaplan-Meier method is used for survival analysis. Cox regression analysis was used to predict factor affecting survival. SAS software version 6.2 (SAS Institute, 
Cary, NC) was used for analysis of the result. Definition of the overall survival as the period from enrollment to the date of death from any cause or last follow-up. Progression-free survival is defined as the interval from enrollment of patients, to the time of disease relapse or progression.

\section{Result}

\section{- Patients characteristics}

Among 130 patients of advanced ovarian carcinoma (III/IV), 66 patients received neoadjuvant chemotherapy (TC) followed by interval debulking surgery (NACT-IDS, the group I) and 64 patients underwent primary debulking surgery followed by postoperative chemotherapy(PDS-ACTR, the group II). No statistical significant difference between the two groups as regard patient's characteristic criteria including age, PS, histopathology, and serum level of CA125 (Table 1).

\section{- The result of surgery in both groups}

The rate of complete resection with no residual disease was significantly higher in patients with NACT-IDS group versus PDS-ACTR group $(76.9 \%$ vs $54 \%, \mathrm{P}=0.03$ ) (Table 2). Also, the following post-operative morbidity such as;

Table 1. Patient's characteristics comparison between both groups.

\begin{tabular}{|c|c|c|c|c|}
\hline \multicolumn{2}{|c|}{ Variables } & \multirow{2}{*}{$\begin{array}{c}\text { NACT-IDS } \\
61\end{array}$} & \multirow{2}{*}{$\begin{array}{c}\text { PDS-ACTR } \\
63\end{array}$} & \multirow{3}{*}{$\begin{array}{c}\text { P-value } \\
\text { NS }\end{array}$} \\
\hline & Median & & & \\
\hline Age & Range & $42-74$ & $39-78$ & \\
\hline \multirow{6}{*}{ Histopathology } & Total & 66 & 64 & \multirow{6}{*}{ NS } \\
\hline & Serous & $42(65 \%)$ & $40(63 \%)$ & \\
\hline & Mucinous & $13(20 \%)$ & $12(19 \%)$ & \\
\hline & Clear & $3(4 \%)$ & $2(3 \%)$ & \\
\hline & Endometroid & $5(7 \%)$ & $6(9 \%)$ & \\
\hline & Undiffertiated & $3(4 \%)$ & $4(6 \%)$ & \\
\hline \multirow{3}{*}{ Figo Stage } & IIIB & $9(14 \%)$ & $12(19 \%)$ & \multirow{3}{*}{ NS } \\
\hline & IIIC & $49(74 \%)$ & $45(70 \%)$ & \\
\hline & IV & $8(12 \%)$ & $7(11 \%)$ & \\
\hline \multirow{3}{*}{ CA125 level } & Normal & $6(9 \%)$ & $7(11 \%)$ & \multirow{3}{*}{ NS } \\
\hline & $<500$ & $38(58 \%)$ & $42(66 \%)$ & \\
\hline & $>500$ & $22(33 \%)$ & $15(23 \%)$ & \\
\hline
\end{tabular}

Table 2. Degree of surgical debulking between both groups.

\begin{tabular}{ccccc}
\hline \multicolumn{2}{c}{ Variables } & NACT-IDS $(\mathbf{n}=\mathbf{6 6})$ & PDS-ACTR $(\mathbf{n}=64)$ & P-value \\
\hline \multicolumn{2}{c}{ TBSO/Omentectomy } & $65(98 \%)$ & $59(92 \%)$ & NS \\
\multicolumn{2}{r}{ Optimal cytoreduction } & $50(76.9 \%)$ & $32(54 \%)$ & 0.03 \\
& Total & 15 & 27 & 0.002 \\
Suboptimal & $<1 \mathrm{~cm}$ & 8 & 7 & \\
Cytoreduction & $\mathbf{1 . 1 - 2}$ & 4 & 13 & 0.002 \\
& $>\mathbf{c m}$ & 3 & 7 & \\
\hline
\end{tabular}


bowel resection, urinary bladder injury, blood loss, deep venous thrombosis (DVT), hospitalization and ICU admission were significantly lower in a group received NACT-IDS (Table 3).

\section{- Survival analysis}

The median time of follow up was 36-month range from (8 - 42 month). The progression-free survival (PFS) tended to be significantly improved in NACTIDS group in comparison to whom underwent PDS-ACTR group (mPFS, 20 months vs. 15 months respectively, $\mathrm{P}$ value $=0.002$ [log rank test], HR: 2.661, 95\% CI 1.269 - 5.582) (Figure 5).

There is significant difference in Overall survival between NACT-IDS group and PDS-ACTR group (mOS, 27 months vs. 18 months respectively, $\mathrm{P}$ value $=$ 0.04 [log rank test], HR: 2.661, 95\% CI 1.269 - 5.582) (Figure 6). Cox regression analysis showed significant factors predicted survival is residual tumor volume in both groups, Cox proportional hazard models demonstrated both macroscopic residuals $(>2 \mathrm{~cm}, \mathrm{P}=0.002)$ (odds ratio, 1.47; 95\% confidence interval (95\% $\mathrm{CI}),(1.23$ - 1.77; $\mathrm{P}=0.002)$ and response to neoadjuvant chemotherapy $(\mathrm{P}=$ 0.03 ) (odds ratio, 1.67; 95\% confidence interval (95\% CI), (1.34 - 2.07; $\mathrm{P}=0.03$ ) to be the most statistically significant predictive survival variables (Table 4).

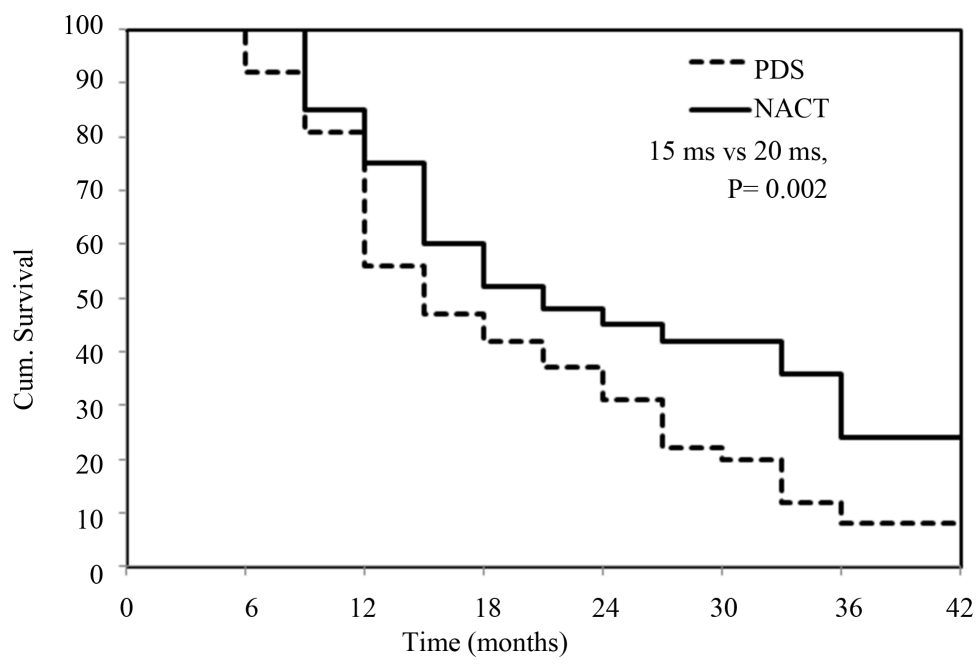

Figure 5. Graphical presentation of progression free survival in NACT and PDS groups.

Table 3. Surgical morbidities between both groups.

\begin{tabular}{cccc}
\hline Variables & NACT-IDS & PDS-ACTR & P-value \\
\hline Urinary bladder injury & 4 & 9 & 0.02 \\
Bowel injury & 0 & 3 & 0.02 \\
ICU stay & 1.9 & 4.2 & 0.02 \\
Hospital stay & 8.7 & 15 & 0.03 \\
DVT & 5 & 12 & NS \\
Blood loss & 430 & 720 & 0.001 \\
Blood transfusion & $1(500 \mathrm{cc})$ & $4(500 \mathrm{cc})$ & 0.02 \\
\hline
\end{tabular}




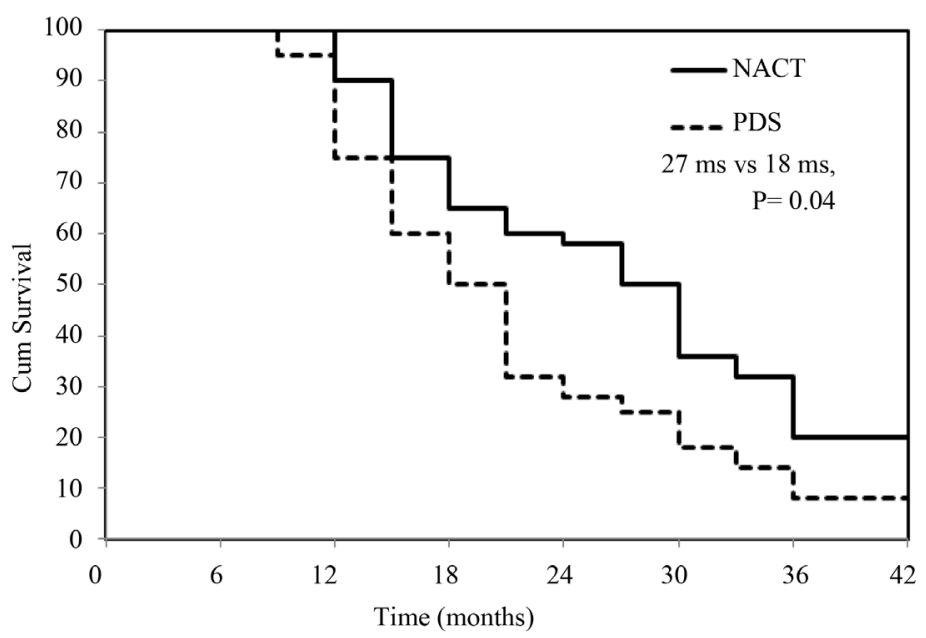

Figure 6. Graphical presentation of overall free survival in NACT and PDS.

Table 4. Multivariate Cox regression analysis of both groups for overall survival.

\begin{tabular}{|c|c|c|c|c|c|c|}
\hline \multicolumn{2}{|c|}{ factor } & No. of cases & OCR deaths $(\% \mid)$ & HR & CI $(95 \%)$ & $\mathrm{P}$-value \\
\hline \multirow{5}{*}{$\begin{array}{c}\text { Age at } \\
\text { diagnosis }\end{array}$} & $50-55$ & 32 & $15(46.8 \%)$ & 0.67 & $0.47-0.95$ & \multirow{4}{*}{0.06} \\
\hline & $56-60$ & 40 & $18(45 \%)$ & 0.64 & $0.73-1.02$ & \\
\hline & $61-65$ & 33 & $21(63.3 \%)$ & 0.88 & $0.64-1,12$ & \\
\hline & $65-70$ & 25 & 19 (76\%) & 1.03 & $0.75-1.23$ & \\
\hline & Serous & 82 & $49(59.7 \%)$ & 0.98 & $0.67-1.34$ & \multirow{5}{*}{0.76} \\
\hline \multirow{4}{*}{ Histology } & Mucinous & 25 & $14(56 \%)$ & 1.00 & $0.65-1.23$ & \\
\hline & Clear cell & 5 & $3(60 \%)$ & 089 & $0.71-1.29$ & \\
\hline & Endometroid & 11 & $6(54 \%)$ & 0.93 & $0.68-1.34$ & \\
\hline & Undifferetiated & 7 & $4(57 \%)$ & 097 & $0.71-1.34$ & \\
\hline \multirow[b]{2}{*}{ Stage } & III & 115 & $79(68.6 \%)$ & 1 & - & \multirow[b]{2}{*}{0.01} \\
\hline & IV & 15 & $11(73.3 \%)$ & 0.5 & $0.61-0.85$ & \\
\hline \multirow{3}{*}{$\begin{array}{c}\text { Grade of } \\
\text { differetiation }\end{array}$} & Well & 60 & $20(30 \%)$ & 1 & - & \multirow{3}{*}{0.06} \\
\hline & Moderate & 40 & $25(62 \%)$ & 1.34 & $0.98-1.67$ & \\
\hline & Poor & 30 & $21(70 \%)$ & 1.54 & $0.87-1.87$ & \\
\hline \multirow{3}{*}{$\begin{array}{l}\text { Residual } \\
\text { tumor }\end{array}$} & 0 & 82 & $23(28 \%)$ & 1 & - & \multirow{3}{*}{0.002} \\
\hline & $\leq 2 \mathrm{~cm}$ & 32 & $10(31.3 \%)$ & 1.33 & $1.07-1.64$ & \\
\hline & $>2 \mathrm{~cm}$ & 10 & $6(60 \%)$ & 1.47 & $1.23-1.77$ & \\
\hline Response to & Responding & 49 & $30(61 \%)$ & 1 & - & \multirow{2}{*}{0.03} \\
\hline NACT & No responding & 16 & $12(75 \%)$ & 1.67 & $1.34-2.07$ & \\
\hline
\end{tabular}

\section{Discussion}

Management of ovarian cancer is one of highest confrontation in oncology, but unfortunately $70 \%$ of patients presented in advanced stage (III, IV) and approximately half of them die from cancer, making it one of the leading cause of 
gynecologic-cancer related death [15]. Primary debulking surgery has become the favored first step in the management of advanced ovarian cancer [7]. Our purpose aims to evaluate the upfront role of neoadjuvant chemotherapy followed by interval debulking surgery (NACT-IDS) in advanced ovarian cancer (III/IV) versus primary debulking surgery followed by chemotherapy (PDS-ACTR). Our results showed that the rate of attaining complete resection with no residual disease was significantly higher in patients with NACT-IDS versus PDS-ACTR $(\mathrm{P}=0.03)$. The patient underwent NACT-IDS show less surgical invasiveness and less postoperative morbidity such as; bowel resection, urinary bladder injury, blood loss, deep venous thrombosis (DVT), hospitalization and ICU admission. The previous reports exposed complete resection in NACT-IDS after neoadjuvant chemotherapy ranging from $75 \%$ to $90 \%$. Neoadjuvant chemotherapy decreases tumor volume and facilitates surgical procedures especially chemosensitive tumor which had completed or partial clinical response achievement in $76 \%$ of patients with less residual volume which had an impact of decrease morbidity and mortality and improving clinical outcome [16]-[23]. Analysis of our data showed significant improvement in both progression-free survival and overall survival in those underwent NACT-IDS compared to PDS-ACTR these results comparable to those published by Kuhn et al. [24] [25], Rose et al., and Muggia et al. [6] [24] [25] [26], they showed prolonged survival times and significantly better median survival in NACT group than the conventional PDS-ACTR. According to data published by Onnis et al. [18] and Surwit et al. [24], they described patients treated with NACT-IDS compared with those underwent conventional PDS followed by chemotherapy; They found that overall survival was not upgraded. Analysis of data reported by Schwartz et al. [16] and Vergote et al. [22] patients treated with NACT followed by PDS still obtained similar survival compared to those undergoing conventional primary surgery. This disagreement might be due to different patient characteristics and dissimilar treatment regimens. Multivariate analysis of previous data suggests the primary goal for best management and excellent outcome of these patients to reach to no residual tumor volume which can achieve by NACT-IDS with less surgical morbidity and better survival (19.20 - 31.32). In our data, show a residual tumor, response to chemotherapy and staging (III) are the most statistically significant predictive variables adversely affecting survival.

\section{Conclusion}

NACT-IDS for advanced ovarian cancer (III/IV) resulted in higher frequency of complete resection with no residual tumor, less post-operative surgical morbidity and a significant increase in both progression-free and overall survival. Further prospective study with more number of patients is highly recommended.

\section{References}

[1] Ferlay, J., Steliarova-Foucher, E., Lortet-Tieulent, J., Rosso, S., Coebergh, J.-W.W., Comber, H., et al. (2013) Cancer Incidence and Mortality Patterns in Europe: Esti- 
mates for 40 Countries in 2012. European Journal of Cancer, 49, 1374-1403. https://doi.org/10.1016/j.ejca.2012.12.027

[2] Group USCSW (2010) United States Cancer Statistics: 1999-2006 Incidence and Mortality Web-Based Report. Atlanta US Dep Heal Hum Serv Centers Dis Control Prev Natl Cancer Inst.

[3] Meyer, J.I., Kennedy, A.W., Friedman, R., Ayoub, A. and Zepp, R.C. (1995) Ovarian Carcinoma: Value of CT in Predicting Success of Debulking Surgery. American Journal of Roentgenology, 165, 875-878. https://doi.org/10.2214/ajr.165.4.7676985

[4] Bristow, R.E., Duska, L.R., Lambrou, N.C., Fishman, E.K., O’Neill, M.J., Trimble, E.L., et al. (2000) A Model for Predicting Surgical Outcome in Patients with Advanced Ovarian Carcinoma using Computed Tomography. Cancer, 89, 1532-1540. https://doi.org/10.1002/1097-0142(20001001)89:7<1532::AID-CNCR17>3.0.CO;2-A

[5] Harter, P., Gnauert, K., Hils, R., Lehmann, T.G., Fisseler-Eckhoff, A., Traut, A., et al. (2007) Pattern and Clinical Predictors of Lymph Node Metastases in Epithelial Ovarian Cancer. International Journal of Gynecological Cancer, 17, 1238-1244. https://doi.org/10.1111/j.1525-1438.2007.00931.x

[6] Maggioni, A., Panici, P.B., Dell'Anna, T., Landoni, F., Lissoni, A., Pellegrino, A., et al. (2006) Randomised Study of Systematic Lymphadenectomy in Patients with Epithelial Ovarian Cancer Macroscopically Confined to the Pelvis. British Journal of Cancer, 95, 699-704. https://doi.org/10.1038/sj.bjc.6603323

[7] Lou, E., Vogel, R.I., Gerber, M., Grad, A., Monu, M., Łukaszewski, T., et al. (2017) Prospective Assessment of Circulating Tumor Cells (CTCs) in Women Undergoing Surgery for Suspected Ovarian Cancer. Gynecologic Oncology, 145, 92. https://doi.org/10.1016/j.ygyno.2017.03.215

[8] Eisenkop, S.M., Spirtos, N.M., Montag, T.W., Nalick, R.H. and Wang, H.J. (1992) The Impact of Subspecialty Training on the Management of Advanced Ovarian Cancer. Gynecologic Oncology, 47, 203-209. https://doi.org/10.1016/0090-8258(92)90107-T

[9] Frei 3rd, E. (1982) Clinical Cancer Research: An Embattled Species. Cancer, 50, 1979-1992.

https://doi.org/10.1002/1097-0142(19821115)50:10<1979::AID-CNCR2820501002> 3.0.CO;2-D

[10] Sujlana, P., Skrok, J. and Fayad, L.M. (2017) Review of Dynamic Contrast-Enhanced MRI: Technical Aspects and Applications in the Musculoskeletal System. Journal of Magnetic Resonance Imaging. https://doi.org/10.1002/jmri.25810

[11] Bellaton, E., Bertozzi, A.I., Behar, C., Chastagner, P., Brisse, H., Sainte-Rose, C., et al. (2003) Neoadjuvant Chemotherapy for Extensive Unilateral Retinoblastoma. British Journal of Ophthalmology, 87, 327-329. https://doi.org/10.1136/bjo.87.3.327

[12] Ansquer, Y., Leblanc, E., Clough, K., Morice, P., Dauplat, J., Mathevet, P., et al. (2001) Neoadjuvant Chemotherapy for Unresectable Ovarian Carcinoma: A French Multicenter Study. Cancer, 91, 2329-2334. https://doi.org/10.1002/1097-0142(20010615)91:12<2329::AID-CNCR1265>3.0.CO; $\underline{2-\mathrm{U}}$

[13] Deraco, M., Raspagliesi, F. and Kusamura, S. (2003) Management of Peritoneal Surface Component of Ovarian Cancer. Surgical Oncology Clinics of North America, 12, 561-583. https://doi.org/10.1016/S1055-3207(03)00027-9

[14] Michielsen, K., Dresen, R., Vanslembrouck, R., De Keyzer, F., Amant, F., Mussen, E., et al. (2017) Diagnostic Value of Whole Body Diffusion-Weighted MRI Compared to Computed Tomography for Pre-Operative Assessment of Patients Suspected for Ovarian Cancer. European Journal of Cancer, 83, 88-98. 
https://doi.org/10.1016/j.ejca.2017.06.010

[15] Randall, T.C. and Rubin, S.C. (2001) Cytoreductive Surgery for Ovarian Cancer. Surgical Clinics of North America, 81, 871-883. https://doi.org/10.1016/S0039-6109(05)70171-7

[16] Schwartz, P.E., Rutherford, T.J., Chambers, J.T., Kohorn, E.I. and Thiel, R.P. (1999) Neoadjuvant Chemotherapy for Advanced Ovarian Cancer: Long-Term Survival. Gynecologic Oncology, 72, 93-99. https://doi.org/10.1006/gyno.1998.5236

[17] Vergote, I., De Wever, I., Tjalma, W., Van Gramberen, M., Decloedt, J. and van Dam, P. (1998) Neoadjuvant Chemotherapy or Primary Debulking Surgery in Advanced Ovarian Carcinoma: A Retrospective Analysis of 285 Patients. Gynecologic Oncology, 71, 431-436. https://doi.org/10.1006/gyno.1998.5213

[18] Kayikcioglu, F., Kose, M.F., Boran, N., Caliskan, E. and Tulunay, G. (2001) Neoadjuvant Chemotherapy or Primary Surgery in Advanced Epithelial Ovarian Carcinoma. International Journal of Gynecological Cancer, 11, 466-470. https://doi.org/10.1046/j.1525-1438.2001.01064.x

[19] Vergote, I., de Wever, I., Tjalma, W., Van Gramberen, M., Decloedt, J. and Van Dam, P. (2000) Interval Debulking Surgery: An Alternative for Primary Surgical Debulking? Seminars in Surgical Oncology, 19, 49-53. https://doi.org/10.1002/1098-2388(200007/08)19:1<49::AID-SSU8>3.0.CO;2-Z

[20] Onda, T., Kobayashi, H., Nakanishi, T., Hatae, M., Iwasaka, T., Konishi, I., et al. (2009) Feasibility Study of Neoadjuvant Chemotherapy Followed by Interval Debulking Surgery for Stage III/IV Ovarian, Tubal, and Peritoneal Cancers: Japan Clinical Oncology Group Study JCOG0206. Gynecologic Oncology, 113, 57-62. https://doi.org/10.1016/j.ygyno.2008.12.027

[21] Schwartz, P.E. (2002) Neoadjuvant Chemotherapy for the Management of Ovarian Cancer. Best Practice \& Research: Clinical Obstetrics \& Gynaecology, 16, 585-596. https://doi.org/10.1053/beog.2002.0304

[22] Vergote, I., Amant, F., Kristensen, G., Ehlen, T., Reed, N.S. and Casado, A. (2011) Primary Surgery or Neoadjuvant Chemotherapy Followed by Interval Debulking Surgery in Advanced Ovarian Cancer. European Journal of Cancer, 47, S88-S92. https://doi.org/10.1016/S0959-8049(11)70152-6

[23] Lee, S., Kim, B., Lee, J., Park, C., Lee, J. and Bae, D. (2006) Preliminary Results of Neoadjuvant Chemotherapy with Paclitaxel and Cisplatin in Patients with Advanced Epithelial Ovarian Cancer Who Are Inadequate for Optimum Primary Surgery. Journal of Obstetrics and Gynaecology Research, 32, 99-106. https://doi.org/10.1111/j.1447-0756.2006.00359.x

[24] Surwit, E., Childers, J., Atlas, I., Nour, M., Hatch, K., Hallum, A., et al. (1996) Neoadjuvant Chemotherapy for Advanced Ovarian Cancer. International Journal of Gynecological Cancer, 6, 356-361.

https://doi.org/10.1046/j.1525-1438.1996.06050356.x

[25] Kuhn, W., Rutke, S., Späthe, K., Schmalfeldt, B., Florack, G., von Hundelshausen, B., et al. (2001) Neoadjuvant Chemotherapy Followed by Tumor Debulking Prolongs Survival for Patients with Poor Prognosis in International Federation of Gynecology and Obstetrics Stage IIIC Ovarian Carcinoma. Cancer, 92, 2585-2591. https://doi.org/10.1002/1097-0142(20011115)92:10<2585::AID-CNCR1611>3.0.CO; $\underline{2-\#}$

[26] Rose, P.G. (2002) A Phase III Randomized Study of Interval Secondary Cytoreduction in Patients with Advanced Stage Ovarian Carcinoma with Suboptimal Residual Disease: A Gynecologic Oncology Group Study. Proceedings of American Society of Clinical Oncology, 21, 201a. 